\title{
THE PROGNOSIS OF IDIOPATHIC HYPOCHROMIC ANAEMIA
}

\author{
By John W. B. Forshaw, M.A., M.D.(Camb.), M.R.C.P. \\ Medical Registrar, Liverpool Stanley Hospital
}

Moore (1950) considers that there is no justification now for describing hypochromic anaemia as idiopathic because iron deficiency never develops unless iron is lost from the body in repeated pregnancies, chronic haemorrhage or normal menstruation. In this paper, however, the description of idiopathic has been given to those cases in which hypochromic anaemia is the primary diagnosis, in order to distinguish them from those cases in which the anaemia is obviously secondary to some other disease.

The credit for first emphasizing the value of iron therapy in chlorosis belongs to Sydenham (1692), but Blaud (1832) raised iron to its status as the specific treatment of chlorosis. Blaud pointed out that in order to prevent relapse the iron treatment should be continued for some time after the cure, and Allbutt (1909) observed the tendency for chlorosis to relapse in later life.

In the disease, which has been variously described as simple achlorhydric anaemia (Witts, I930), primary hypochromic anaemia (Damashek, 1933) and idiopathic hypochromic anaemia (Wintrobe and Beebe, I933), the respective authors all found that although the immediate results of iron therapy were good, the late results were most unsatisfactory, and this was because of the ten. dency to relapse when treatment was stopped. Witts (1930) also observed that the poor prognosis as regards recovery of the anaemia was partly due to the fact that women with hypochromic anaemia would tolerate a state of continued ill-health rather than submit to the discipline of treatment.

Heath and Patek (1937) found that relapse of the anaemia following the cessation of iron therapy only occurred in patients in whom pathological blood loss, particularly menorrhagia, continued. On the other hand, Davidson and Fullerton (1938) found that relapse did occur in patients with normal menses, although in patients who had passed the menopause it only occurred if there was some other source of blood loss. Probably one of the main factors responsible for the different reports on the association between persistent menorrhagia and a relapse is the variable opinion of the amount of blood loss which can be defined as menorrhagia.

Hypochromic anaemia in the absence of haemorrhage is rare in men, but in the small number of cases which have been reported, the prognosis as regards the anaemia has been very good. Burger and Witts (1934) followed up most of their 26 male patients for from one to ten years after the cessation of iron treatment and none relapsed, and Shorthouse and King (195I) found that out of 20 male patients who were followed up for from three months to two years after stopping treatment, none relapsed.

These previous observations show fairly definitely that the prognosis of idiopathic hypochromico anaemia in men is good, and that after correcting the anaemia further iron therapy is not required. In women, who form the majority of these patients, however, the prognosis after cessation of iron therapy cannot be predicted with certainty. Both continuous iron therapy (Witts, 1930; Damashek, 1933) and periodical treatment with large doses of iron (Meulengracht, 1932) have been advocated. As a relapse is by no means invariable, Davidson and Fullerton (1938) considered that it was not necessary to order iron routinely for the prevention of a relapse in women past the menopause, and in pre-menopausal women without menorrhagia iron treatment need not be continued, provided that the patients were examined at six-monthly intervals. It is the fact that a relapse after the cessation of iron therapy is unpredictable which makes the continued treatment of hypochromic anaemia more difficult than that of pernicious anaemia in which a relapse is invariable if the specific treatment is stopped.

\section{Present Investigation}

The unsatisfactory results of treatment which have been reported previously, prompted the present investigation to determine whether the prognosis was still poor, and if so, to investigate 
the responsible factors. The review is of 110 patients ( 96 females and 14 males), who first attended either the David Lewis Northern Hospital, the Liverpool Stanley Hospital, Broadgreen Hospital or Wallasey Central Hospital between one and ten years previously, and their last attendance was never less than one year previously. All these patients had been given a primary diagnosis of hypochromic anaemia, microcytic anaemia or iron deficiency anaemia, and cases in which the anaemia was obviously secondary to some other disease have not been included. All cases had a colour index below $0.8 \mathrm{I}$ and a haemoglobin value below $7 \mathrm{I}$ per cent. (ro.5 g.) at the time of their original attendance.

A letter was sent to all these patients, asking them to attend hospital, and 77 patients $(67$ females and 10 males) kept their appointment. A questionnaire was sent to the remaining 33 patients, and also a letter was sent to their general practitioners asking for information about their progress and present condition. Eleven patients returned the questionnaire and the general practitioners gave some information about another 12 patients. Additional information about nine patients was received from other hospitals. Ten patients were not traced.

\section{Results}

The original diagnosis was found to be definitely wrong in six patients. One patient had frequent attacks of melaena due to bleeding from a stomal ulcer shortly after attending with anaemia. In one patient a chest $\mathrm{X}$-ray, which was taken at another hospital five months after her first attendance, showed evidence of active pulmonary tuberculosis; this mistaken diagnosis, however, could not have been avoided because a chest $\mathrm{X}$-ray, taken at the time of her original attendance, was normal. Four patients were reported to have died from carcinoma of the stomach within two years of attending with anaemia, although the diagnosis was confirmed by post-mortem examination in only one patient; two of these patients had had barium meal X-rays, both of which were normal. Other conditions which became evident after first attending with anaemia were gastrointestinal bleeding in two patients and chronic nephritis and haematuria in one patient respectively. It is not at all certain, however, that these conditions were present when the patients first attended with anaemia.

The prognosis as regards life was good, and apart from the four patients with carcinoma of the stomach, only three patients had died. The cause of death in two of these patients was suicide and chronic nephritis respectively, and was obviously not related to the anaemia. The other patient, who had attended originally with the气 Plummer-Vinson syndrome, died one year later $\frac{\mathrm{Q}}{\mathrm{C}}$ from carcinoma of the pharynx.

There appeared to be a definite psychogenic. overlay in a number of female patients, whose $\overrightarrow{\vec{F}}$ symptoms persisted after the anaemia had beencorrected. Out of 35 women whose haemoglobin듬 value was 80 per cent. or above at the time of $\overline{\bar{n}}$ their follow-up attendance, i I still complained of $\overrightarrow{\mathbb{D}}$ either lassitude or dyspnoea or both. One of these patients had mitral stenosis and one had"s emphysema to account for their symptoms, but $\overrightarrow{0}$ in the remaining patients the symptoms must $\overrightarrow{-}$ have been mainly psychogenic. On the other hand, some of the women had no symptoms wheno their haemoglobin was at a low level. Out of 3 nine patients whose haemoglobin value was belowi. 50 per cent. at the time of their follow-up attend- $\omega$ ance, two had no symptoms and one felt better ${ }^{\circ}$ although the haemoglobin value had fallen. In addition, out of 22 patients whose haemoglobin $\vec{v}$ value was between 50 and 70 per cent. at the timeo of their follow-up attendance, five had no symp-toms. Psychogenic symptoms were not evident in the male patients, none of whom had anyo symptoms after the anaemia had been corrected. 요

In the males the prognosis as regards recovegy $\vec{\varphi}$ of the anaemia was good. The haemoglobin value was above 84 per cent. in nine of the tefi patients who kept their appointment, and in theo other patient the haemoglobin value had risens from 50 to 66 per cent. although he had nevero taken any iron. One other patient wrote to say that he was feeling very well and that he was in the Army, and another patient, who did noto attend, had been followed-up previously for over 3 a year without relapse. The continuation of iron therapy was not necessary to prevent a relapse, and only two patients had taken iron regularly국 since leaving hospital. Four patients had nottaken any iron for over a year, and four patients 3 had not taken it for several months.

In the females the prognosis as regards recovery of the anaemia was bad. In 36 (53 per cent.) of 67 female patients who were followed-up for over a year, the haemoglobin value was below 75 pero cent., and in 18 (27 per cent.) it was below 60 per cent. In 15 of these patients the haemoglobino value had either increased or only altered slightlyn since their previous attendance, but in 21 patients the haemoglobin value had dropped considerably $\omega$ In four patients (Nos. 44, 62, 64 and 89) who had attended hospital on several occasions, there was? a history of recurrent relapses.

Information about the progress of another 14 female patients was obtained from answers to the questionnaire and from general practitioners reports. Seven patients said that they had noके 
TABle I

Details of Iron Therapy and Menstrual Function in 36 Patients with Haemoglobin Value below 75 per cent. at the Time of their Follow-UP Attendance

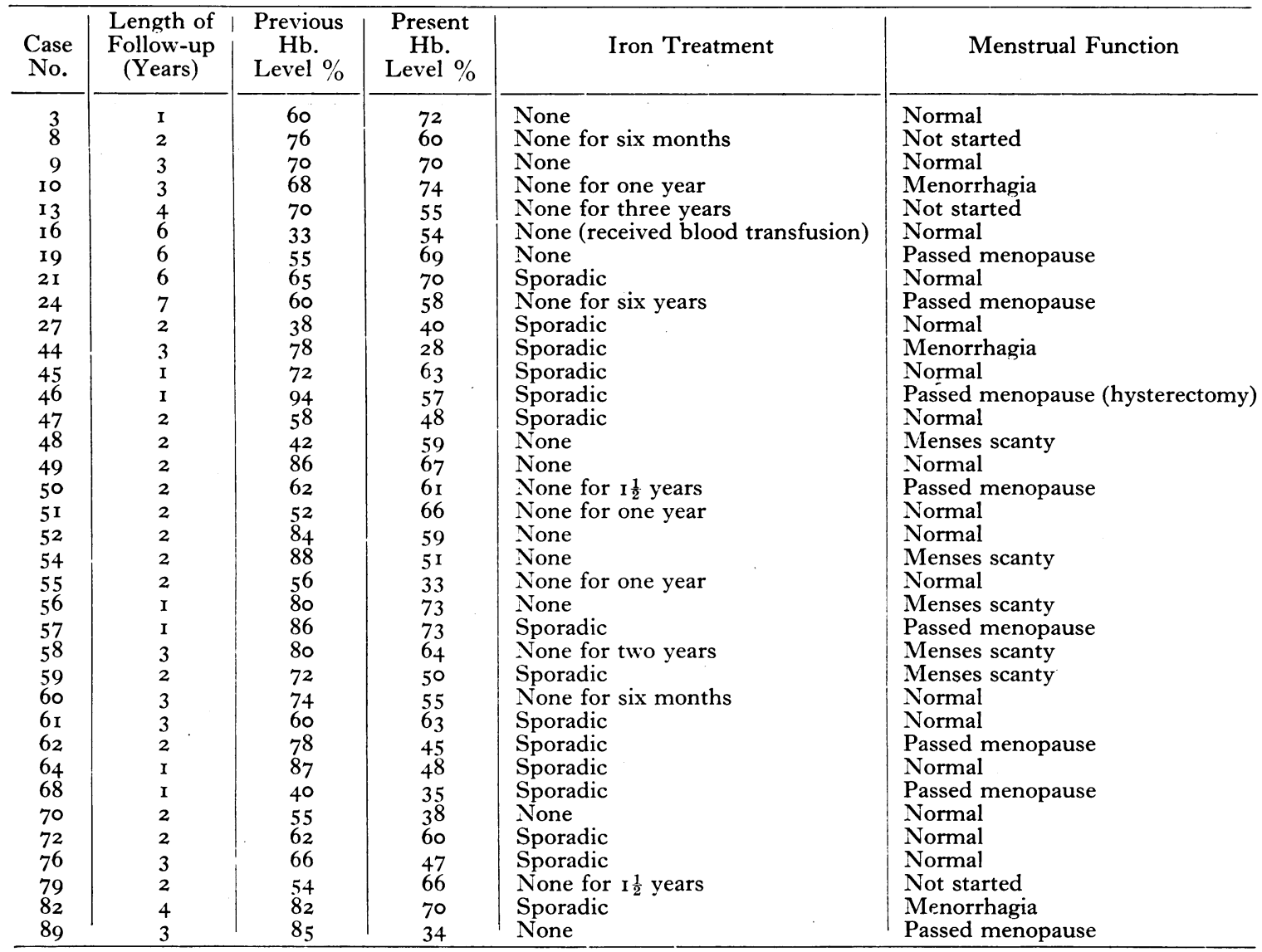

symptoms, and the general practitioners reported that another three patients did not appear anaemic. Two patients were considered by their general practitioners to be still anaemic, and the husband of another patient, who had previously attended hospital for four years with persistent anaemia, wrote to say that his wife was still anaemic, but that, although he had pleaded with her, she would not take her iron treatment, and she would not attend hospital. The other patient said that she had had a hysterectomy for fibroids, which was confirmed by a letter from another hospital, and that although she was not anaemic now, her dysphagia had persisted.

None of the patients in whom the haemoglobin value was below 75 per cent. had been taking iron regularly. They had either stopped taking it altogether as soon as they felt better, or they continued to take it occasionally if they felt the symptoms returning. The details of iron therapy in these patients are shown in Table I. The reasons usually given for stopping treatment were either that they had not been told that prolonged treatment was required, or that they became tired of the frequent long waits in the doctor's surgery to obtain a new prescription. The impression gained, however, was that these reasons were given often as an excuse for indifference, and this applies particularly to those patients who had recurrent relapses and were urged to continue taking the iron treatment.

Seventeen of the 36 patients with a haemoglobin value below 75 per cent. had normal menses and three had menorrhagia. On the other hand, five patients had scanty menses, seven had passed the menopause, one had had a hysterectomy for fibroids, and in three patients the menses had not yet started. The menstrual function in each of these patients is shown in Table I. Relapse of the anaemia was not entirely dependent on menstruation, and out of the 20 patients who had relapsed, two (Nos. 8 and I3) had not started to 
TABLE 2

Details of Iron Therapy and Menstrual Function in 31 Patients with Haemoglobin Value above 75 Per cent冧 at THE Time of their Follow-UP AtTENDANCE

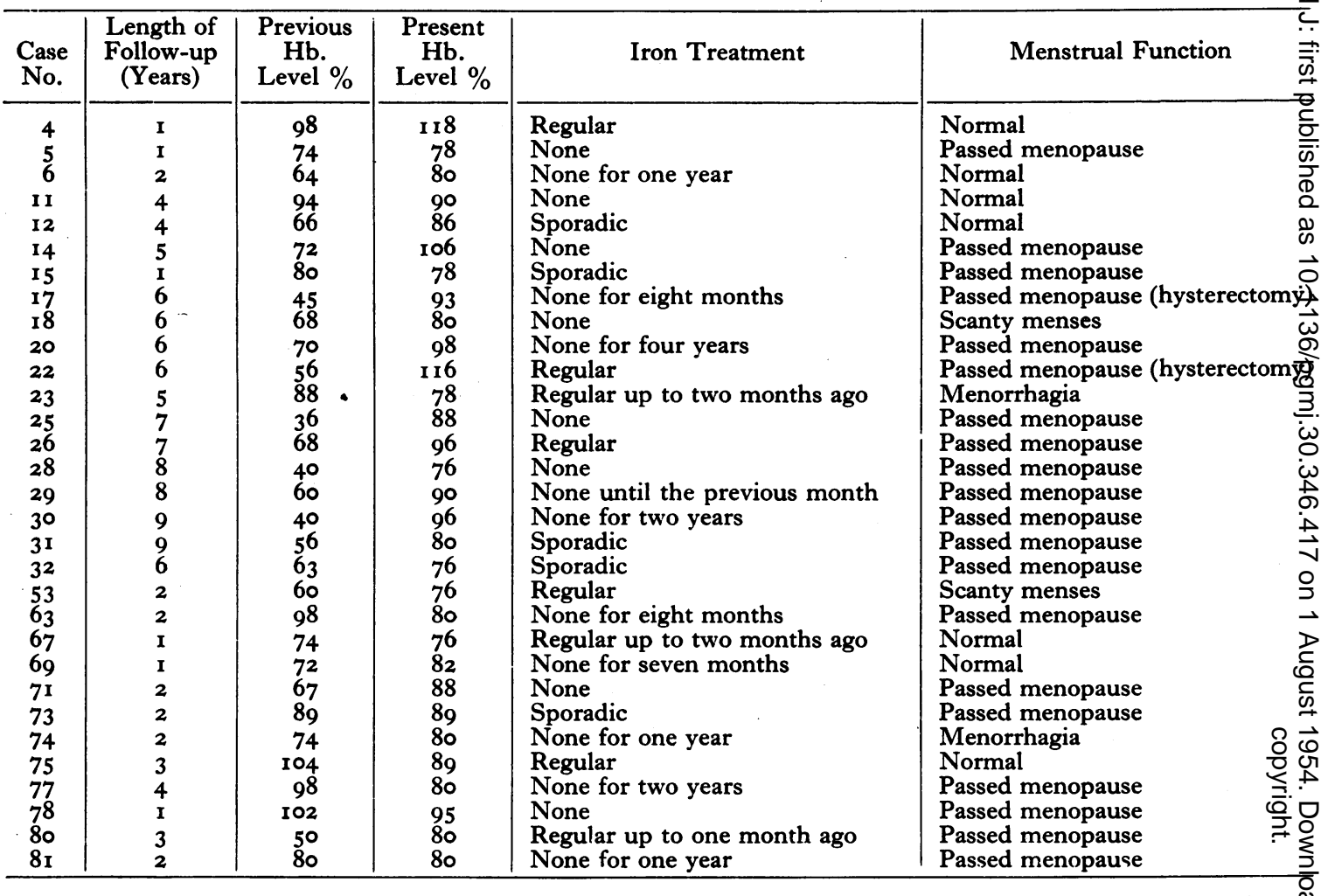

menstruate, four (Nos. 57, 59, 62 and 89) had passed the menopause, and one (No. 46) had had a hysterectomy. On the other hand, of the 12 patients who were menstruating and who had not taken any iron treatment during the previous year, five (Nos. 3, 9, ro, 48 and $5 \mathrm{r}$ ) had not relapsed. The cessation of menorrhagia was probably partly responsible for one patient (No. 5I) not relapsing, although the menorrhagia was relieved by improving the anaemia and was not due to any local disease in the pelvis.

An analysis of the $3 \mathrm{I}$ patients whose haemoglobin values were above 75 per cent. at the time of their follow-up attendance shows that the haemoglobin value had fallen by ro per cent. or more in only three patients (Nos. 23, 63 and 77), but that this could not be regarded as a relapse, because the colour index was about one in each case. In 19 patients there was a considerable rise in the haemoglobin value, and in the remaining nine patients the haemoglobin value showed no significant change. Eight of these patients had been taking iron regularly and the remainder either took it sporadically, or had not taken it during at least the previous seven months. The details of iron therapy in each of these patients shown in Table 2.

Eighteen of these patients had passed the menos pause, two had had a hysterectomy for fibroids? two had scanty menses, seven had normal menses and two had menorrhagia. The menstrual funco tion in each of these patients is shown in Table 2 . These figures show that a considerably largeo number of these patients than the number of those who were still anaemic had passed the menopause. On the other hand, four patient (Nos. 6, I 1, 12 and 69) with normal menses, one patient (No. I8) with scanty menses and one patient (No. 74) with persistent menorrhagia, has not received any iron treatment during at least the previous seven months and yet they had not relapsed. The cessation of menorrhagia was probs ably partly responsible for two of these patient: (Nos. 6 and II) not relapsing, although in botb cases the menorrhagia was relieved by correcting the anaemia, and was not due to any local diseas in the pelvis.

These figures show that there was not the same tedency to relapse in patients who had passed the menopause, although relapse did occur occas 
sionally after the menopause for no apparent reason. Furthermore, although patients who were menstruating usually relapsed if they stopped taking iron, this was not invariable.

Twenty patients had menorrhagia at the time of their first attendance. In seven of these patients the menorrhagia improved with treatment of the anaemia, and although there was a relapse of the anaemia in four patients (Nos. 47, 52,55 and 70 ), the menorrhagia did not return. Five patients had passed the menopause, two patients (Nos. 17 and 46 ) had had a hysterectomy for fibroids, and one patient (No. 32) had had an X-ray induced menopause for metropathia haemorrhagica. The menorrhagia persisted in five patients, in one of whom (No. 44) there was a severe relapse and in another (No. 82) a mild relapse. No local pelvic abnormality was found in two of these patients with persistent menorrhagia (Nos. 23 and 44), but the other three patients would not consent to gynaecological examination. Neither of the two patients who relapsed had taken iron regularly. On the other hand, two out of the four patients who did not relapse had kept to the iron treatment. The other two patients (Nos. Io and 74) had not taken any iron during the previous year. Persistent menorrhagia, therefore, did not invariably produce a relapse after stopping iron therapy.

Enquiry was made about other sources of haemorrhage in all the patients with a haemoglobin level below 75 per cent. and they were asked to bring a specimen of stools for examination for occult blood. Unfortunately, very few patients complied with this request, and the test was done in only 11 cases. There was definite evidence of haemorrhage in only two patients. One (No. 57) had a hiatus hernia and a positive occult blood test on the stools, and the other (No. 46) had bleeding haemorrhoids.

\section{Discussion}

The observations of previous workers that the prognosis as regards the anaemia is good in male patients and poor in female patients has been confirmed. If, as Moore (1953) believes, hypochromic anaemia in male patients is always due to blood loss, then cessation of the haemorrhage would account for the good prognosis. Further haemorrhage would be expected to occur in some patients, however, and yet the absence of relapse in the male patients followed up by Burger and Witts (1934), by Shorthouse and King (195I) and in the present series has been invariable. Haemorrhage was present in five male patients in the present series, but it appeared to be an adequate cause of the anaemia in only one patient. Cessation of the haemorrhage was probably a factor in preventing relapse in two patients who had a haemorrhoidectomy and in one patient who had had his teeth extracted two months before he had originally attended with anaemia. On the other hand, haemorrhage still continued in one patient with haemorrhoids and in one patient with a naevus on his face which was frequently cut by his razor, and this latter patient had not taken any iron during the previous year. The absence of relapse and also the aetiology of the anaemia can, therefore, only be adequately explained in a small number of cases of hypochromic anaemia in male patients.

The main reason for the poor results in the female patients was that only 12 per cent. of the patients had been taking iron regularly. The remainder had either not taken any iron at all or only taken it sporadically. In addition, one-third of the female patients were so unreliable that they had not kept their second appointment at the outpatient clinic. Many women appeared to be indifferent about their health, and, as Witts (I930) observed, they would tolerate a state of continued ill-health rather than submit to the discipline of treatment.

Persistent anaemia was usually associated with normal menstruation but, unlike the cases reported by Heath and Patek (I937), not with pathological blood loss. The prognosis in patients who had passed the menopause was good, and at the time of their follow-up attendance 64 per cent. of the patients with a haemoglobin value above 75 per cent. compared with 22 per cent. of the patients with a haemoglobin value below 75 per cent. had passed the menopause. A relapse occurred occasionally, however, in patients who had passed the menopause and in whom there was no clinical evidence of haemorrhage, and on the other hand relapse was not invariable after stopping treatment in patients with persistent menorrhagia. These findings are difficult to explain, but it is postulated that there is a compensatory increase in iron absorption in the patients with menorrhagia who do not relapse, and that there is inadequate iron absorption in the patients who, without evidence of haemorrhage, relapse after the menopause.

These findings support the view of previous observers that iron treatment need not be continued in post-menopausal women after the anaemia has been corrected. In view, however, of the occasional cases which relapse, and also of the possibility of the anaemia being due to occult bleeding from a neoplasm, it is advisable to re-examine these women at three-monthly intervals during the next year.

As Davidson and Fullerton (1938) have pointed out, it is not necessary to continue iron therapy routinely to prevent relapse in pre-menopausal 
women, provided they are re-examined at sixmonthly intervals. The majority of pre-menopausal women, however, relapse after the cessation of iron therapy, and the poor results after these patients have been discharged from the hospital out-patient department emphasizes the importance of keeping them under continued surveillance. As these patients are so often indifferent about their health, and most unreliable about taking their treatment, the importance of continuing to take the prescribed dose of iron should be emphasized to them. After the cessation of iron therapy it is so important to follow-up the patients that every effort should be made to contact those patients who do not keep their appointments.

\section{Summary}

An investigation of the prognosis of $\mathrm{I}$ Io patients with hypochromic anaemia is described.

The prognosis as regards the anaemia is good in male patients and relapse does not occur after stopping iron therapy.

The prognosis as regards the anaemia is poor in female patients. This is because relapse of the anaemia usually occurs in pre-menopausal women after stopping iron treatment, and few women continue to take iron in adequate dosage. Very occasionally relapse occurs in post-menopausal women without any evidence of haemorrhage, and relapse is not completely invariable in women with menorrhagia after stopping irô therapy.

Emphasis is laid on the importance of keeping pre-menopausal women under continued sui: veillance in order to obtain a good prognosis.

\section{Acknowledgments}

My thanks are due to the physicians of the David Lewis Northern Hospital, the Liverpos Stanley Hospital, Broadgreen Hospital ard Wallasey Victoria Central Hospital, for permission to follow-up their cases. Acknowledgment is also due to Sir Lionel Whitby for his permission to publish this paper, which formed part of a thesis for the Cambridge M.D. degree.

\section{BIBLIOGRAPHY}

ALLBUTT, SIR C. (I009), Allbutt and Rolleston's 'System W. Clinical Medicine,' London, 2nd edition, $v, 681$.

BLAUD, P. (1832), Rev. méd. franc. étrang., I, 337.

BURGER, G. N., and WITTS, L. J. (1934), Guy's Hosp. Re 84, 14 .

DAMASHEK, W. (1933), Ұ. Amer. med. Ass., roo, 540.

DAVIDSON, L. S. P., and FULLERTON, H. W. (1938), Edin. med. $\mathcal{F}$., 45, 193 .

HEATH, C. W., and PATEK, A. J. (r937), Medicine, 16, 267. MEULENGRACHT, E. (1932), Acta. med. scand., 78, 387.

MOORE, C. V. (1950), Blood, 5, 876 .

MOORE, C. V. (1953), Personal communication.

SHORTHOUSE, P. H., and KING, R. C. (195I), Brit. mes 2, 256.

SYDENHAM, T. (1692), 'Processus Integri,' quoted by Farler, W. M. (1936), Ann. med. Hist., 8, 173 .

WINTROBE, M. M., and BEEBE, R. T. (1933), Medicine, 12

WITTS, L. J. (1930), Guy's Hosp. Rep., 80, 253.

\section{HOW TO GET THERE}

An Address Book for the Medical profession, showing how to reach the various Colleges, Societies, Institutes and Hospitals in and near London.

Continued from page 416-F. Mitchell-HegGS, T.D., F.R.C.S.

\section{BIBLIOGRAPHY}

TANNER, N. C. (1942), 'A Slide Operation for Inguinal and Femoral Hernia,'Brit. F. Surg., 29, 285.

EDWARDS, HAROLd (1943), 'Inguinal Hernia,' Brit. f. Surg., 31, 172 .
MCVAY, C. B., and ANSON, B. J. (1949), 'Inguinal and Femotal Hernioplasty,' Surg., Gynec., Obstet., '88, 473.

KOONTZ, A. R. (1948), 'Preliminary Report on the Use Tantalum Mesh in the Repair of Ventral Hernia,' Ann. Sug. 127, 1079. 